\title{
Altered Brain Structure and Function Correlate with Disease Severity and Pain Catastrophizing in Migraine Patients ${ }^{1,2}$
}

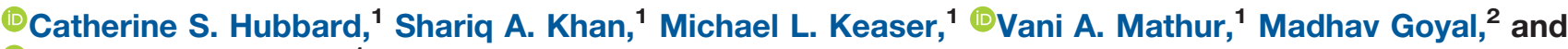 \\ (D)David A. Seminowicz ${ }^{1}$
}

\section{DOI:http://dx.doi.org/10.1523/ENEURO.0006-14.2014}

${ }^{1}$ Department of Neural and Pain Sciences, School of Dentistry, University of Maryland, Baltimore, Maryland 21201, and ${ }^{2}$ Department of Medicine, Johns Hopkins University, Baltimore, Maryland 21218

\begin{abstract}
To investigate the neuroanatomical and functional brain changes in migraine patients relative to healthy controls, we used a combined analytical approach including voxel- and surface-based morphometry along with restingstate functional connectivity to determine whether areas showing structural alterations in patients also showed abnormal functional connectivity. Additionally, we wanted to assess whether these structural and functional changes were associated with group differences in pain catastrophizing and migraine-related disease variables in patients. We acquired T1-weighted anatomical and functional magnetic resonance imaging scans during rest in human subjects with a diagnosis of migraine and healthy controls. Structural analyses revealed greater left hippocampal gray matter volume and reduced cortical thickness in the left anterior midcingulate in patients compared with controls. We also observed negative associations between pain catastrophizing and migraine disease variables and gray matter in areas implicated in processing the sensory, affective, and cognitive aspects of pain in patients. Functional connectivity analyses showed that migraine patients displayed disrupted connectivity between default mode, salience, cognitive, visuospatial, and sensorimotor networks, which was associated with group differences in pain catastrophizing and migraine-related disease variables in patients. Together, our findings show widespread morphological and functional brain abnormalities in migraineurs in affective, cognitive, visual, and pain-related brain areas, which are associated with increased pain catastrophizing, disease chronicity, and severity of symptoms, suggesting that these structural and functional changes may be a consequence of repeated, long-term nociceptive signaling leading to increased pain sensitivity, mood disturbances, and maladaptive coping strategies to deal with unrelenting pain.
\end{abstract}

Key words: chronic pain; gray matter; headache; intrinsic connectivity; neuroimaging; resting-state networks

\section{Significance Statement}

Our study provides a new and comprehensive look at how migraine affects brain structure, how these changes in structure are related to functional brain networks, and how coping and disease severity influence both structure and functional networks. Specifically, we demonstrate concomitant functional and structural brain changes related to pain catastrophizing and disease severity in migraine patients. These findings will have important implications for our understanding of altered brain circuitry associated with the development and progression of migraine and could lead to better treatment options for this patient population. 


\section{Introduction}

Migraine is a debilitating pain condition associated with substantial personal and societal disability (Lipton et al., 2007). Recent neuroimaging studies have demonstrated that migraine patients show widespread functional and structural brain abnormalities relative to healthy controls, and these abnormalities have been associated with migraine-related disease variables, including disease duration and attack frequency, indicating a possible link between the observed anatomical and functional brain changes, symptom severity, and migraine disease progression (Bashir et al., 2013; Maniyar and Goadsby, 2013). Moreover, patients suffering from migraine headaches are more likely to display higher levels of anxiety and maladaptive coping strategies, scoring higher on measures of pain catastrophizing compared with migraine-free individuals, a finding that has been shown to predict impairments in daily functioning and quality of life (Lantéri-Minet et al., 2005; Holroyd et al., 2007; Pires et al., 2013).

To quantify brain structural changes, the two common approaches include voxel-based morphometry (VBM) and surface-based analysis (SBA). VBM is a voxelwise approach that provides an estimate of regional gray matter volume (GMV) (Ashburner and Friston, 2000, 2001). SBA can be used to examine differences in cortical thickness between migraineurs and healthy controls. The benefit of SBA is that it utilizes gyral and sulcal geometry to account for anatomical variability of the cortical surface and therefore provides a direct measure of cortical thickness with subvoxel precision (Fischl and Dale, 2000; Hinds et al., 2008). VBM studies have reported that migraine patients have altered cortical and subcortical GMV, including areas involved in processing the sensory-discriminative, affective, and cognitive-evaluative aspects of pain, as well as increased GMV in brainstem structures such as the periaqueductal gray (PAG) and dorsolateral pons, known to play a critical role in descending pain modulation (Rocca et al., 2006; Kim et al., 2008; Schmidt-Wilcke

Received August 27, 2014; accepted October 18, 2014; First published November 12, 2014.

${ }^{1}$ Author contributions: M.G. and D.A.S. designed research; S.A.K., M.L.K., and M.G. performed research; C.S.H. and D.A.S. analyzed data; C.S.H., V.A.M., M.G., and D.A.S. wrote the paper.

${ }^{2}$ We thank the University of Maryland Magnetic Resonance Research Center, Dr. Rao Gullapalli and George Makris for their assistance with data collection. We would also like to express our gratitude to all the participants who took part in this study. The authors declare no competing financial interests.

This research was supported by NIH NCCAM 5R01AT007176 (to D.A.S.), K23 1KL2RR025006-01 (to M.G.), Society of General Internal Medicine Founders Award (to M.G.), and generous funds provided by the Department of Neural and Pain Sciences, University of Maryland School of Dentistry, Baltimore, MD (to D.A.S.).

Correspondence should be addressed to Dr. David A. Seminowicz, Department of Neural and Pain Sciences, University of Maryland, Baltimore, School of Dentistry, 650 West Baltimore Street, 8 South, Baltimore, Maryland 21201. E-mail: dseminowicz@umaryland.edu.

DOI:http://dx.doi.org/10.1523/ENEURO.0006-14.2014 Copyright (C) 2014 Hubbard et al.

This is an open-access article distributed under the terms of the Creative Commons Attribution License Attribution-Noncommercial 4.0 International which permits noncommercial reuse provided that the original work is properly attributed. et al., 2008; Schmitz et al., 2008; Valfre et al., 2008). Findings from the few studies conducted using SBA are mixed, with some showing increased (Granziera et al., 2006; DaSilva et al., 2007) and others reporting decreased (Messina et al., 2013) cortical thickness in migraine, and still others finding no group differences (Datta et al., 2011). Thus, in the current study, we use both VBM and SBA approaches and test for the association of gray matter (GM) changes with clinical variables to fully characterize structural brain changes in migraine.

Resting-state functional connectivity (RS-FC) is a functional magnetic resonance imaging (fMRI) method used to detect temporal correlations in spontaneous, lowfrequency oscillations across functionally related and structurally distinct brain regions in the absence of an explicit task. This technique is also well-suited for examining the functional reorganization that occurs within intrinsic brain network circuitry in pathological disease states such as migraine. A common finding in chronic pain is that the resting-state default mode network (DMN) is altered (Baliki et al., 2008), and possibly attributable to increased baseline activity of other cognitive, salience, or sensorimotor networks. Combining structural and functional neuroimaging approaches in migraineurs allows us to assess how brain structural abnormalities and disrupted intrinsic network connectivity are related.

The integration of multimodal imaging techniques to investigate morphological and functional differences in the brains of migraineurs versus healthy controls allows for complementary information to be garnered with regard to structure-function relationships and the underlying pathophysiology of migraine to be further elucidated. The current study is novel in that we employed voxel- and surface-based morphometric techniques such as VBM and SBA, with resting-state fMRI, to quantify whole-brain structural differences in cortical and subcortical pain-related brain regions in migraine patients and healthy controls and ascertain whether these structural differences also showed corresponding abnormalities in functional connectivity. Specifically, we hypothesized that patients would show reductions in GMV and cortical thickness in circuits known to be involved in processing the affective [anterior cingulate cortex, anterior insula (aINS)], sensory-discriminative [somatosensory cortices, posterior cingulate cortex (PCC)], and cognitive-evaluative aspects of pain [dorsolateral prefrontal cortex (DLPFC), anterior midcingulate (aMCC), medial prefrontal cortex (mPFC)] and that these regions would also display aberrant functional connectivity. We also hypothesized that patients would show increased GMV in regions known to be important for pain transmission and its modulation (i.e., thalamus and PAG). Furthermore, in light of previous findings demonstrating higher levels of catastrophizing in migraine, we tested the hypothesis that pain catastrophizing would be related to structural and functional abnormalities in pain-related brain areas in patients. In addition, we sought to determine whether structural and functional abnormalities in patients were linked to measures of disease duration, attack frequency, and migraine pain intensity. We expected disease duration and 
symptom severity measures to be correlated with structural measures and abnormal functional connectivity.

\section{Materials and Methods}

\section{Participants}

Seventeen migraine patients $[13$ females; mean age $=$ 41.71 years (12.20)] and 18 healthy controls [ 14 females; mean age $=38.89$ years $(11.25)$ ] were recruited from campuses, local headache clinics, and through community advertisements. Patients were recruited as part of a larger treatment study to determine the long-term effects of meditation training on alleviating migraine-related symptoms and the efficacy of this intervention toward ameliorating abnormalities in brain structure and function. Diagnosis of migraine was made by a physician using the International Classification of Headache Disorders-II (ICHD-II) criteria (Headache Classification Subcommittee of the International Headache Society, 2004). Inclusion criteria required that all patients had a history of recurring headaches for at least 3 months and a headache frequency greater than four headache days per month (4-15 headaches/month classified as episodic migraine; $\geq 15$ headaches/month classified as chronic migraine). The majority of patients $(14 / 17 ; 82.4 \%)$ reported taking some type of prophylactic medication to prevent migraine attacks, whereas a little over a third $(6 / 17 ; 35.3 \%)$ of these patients also reported taking abortive medications (i.e., triptans). Patients were never asked to refrain from taking any medications used to treat or prevent their headaches. At the clinical visit, which occurred prior to the imaging session, patients were given a 60-item general health questionnaire (GHQ-60; Goldberg, 1978) to assess the presence of mood disorders and insomnia. Informed consent was obtained from each participant prior to commencement of study procedures according to the Declaration of Helsinki and per Institutional Review Board guidelines set forth by the Human Research Protections Office.

\section{Behavioral and clinical measures}

Each participant completed a series of self-report questionnaires including the Profile of Mood States (POMS; McNair et al., 1971), the Pain Catastrophizing Scale (PCS; Sullivan et al., 1995), the Short-Form McGill Pain Questionnaire (SFMPQ; Melzack, 1987), and the Migraine Disability Assessment Scale (MIDAS; Stewart et al., 2000). In addition, migraine disease characteristics including retrospective self-report measures of disease duration (years), attack frequency (number of migraines over the past month, six months, and year), and ratings of migraine pain intensity using a 0 to 10 numerical rating scale (NRS; $0=$ no pain and $10=$ worst pain imaginable) for the past $24 \mathrm{~h}$, past week, and past month were determined. Patients were also asked to rate their current migraine pain intensity using the NRS immediately before and after each scan session.

\section{MRI data acquisition}

All participants underwent a single scan session consisting of a high-resolution T1-weighted MP-RAGE anatomi- cal scan [144 slices, FOV $=230 \mathrm{~mm}$, echo time $(T E)=$ $3.44 \mathrm{~ms}$, repetition time $(\mathrm{TR})=2500 \mathrm{~ms}$, flip angle $=9.0^{\circ}$, resolution $=0.9 \times 0.9 \mathrm{~mm}$, matrix size $=256 \times 256 \mathrm{~mm}$, slice thickness $=1 \mathrm{~mm}$, no gap] and a resting-state T2-weighted echo-planar imaging volume functional scan in which the participant was instructed to relax with eyes open (spin-echo, 194 volumes, 36 slices, FOV $=230 \mathrm{~mm}$, $\mathrm{TE}=30 \mathrm{~ms}, \mathrm{TR}=2500 \mathrm{~ms}$, flip angle $=90^{\circ}$, matrix size $=128 \times 128 \mathrm{~mm}$, resolution $=1.8 \times 1.8 \mathrm{~mm}$, slice thickness $=4 \mathrm{~mm}$, no gap, oblique slices). All images were acquired with a Siemens 3T Tim Trio MRI scanner equipped with a 12-channel head coil. Two 10 min functional scans (during a cognitive and pain-related task) followed by a diffusion tensor imaging scan were also acquired after the resting-state scan (data to be presented in a separate report). Total scan time was approximately $50 \mathrm{~min}$.

\section{Voxel-based morphometry}

We performed VBM to determine whether patients differed from controls in regional GMV in cortical and subcortical brain regions. All data preprocessing was accomplished using the VBM8 toolbox (version r435; http://dbm.neuro.uni-jena.de/vbm/). T1-weighted structural images were first segmented into GM, white matter (WM) and CSF, and then spatially normalized to MNI space (Ashburner and Friston, 2000; Mechelli et al., 2005) with DARTEL (Ashburner, 2007). Normalized images were resampled to a voxel size of $1.5 \times 1.5 \times 1.5 \mathrm{~mm}^{3}$, the default resolution used in VBM8. Segmented tissue maps were modulated with Jacobian determinants using the deformation fields obtained during spatial normalization and then smoothed with an $8 \mathrm{~mm}$ Gaussian kernel. Whole-brain GMV was calculated for each subject and averaged across each group. An absolute threshold mask of 0.1 was specified in the analyses.

\section{Surface-based analysis}

To determine whether patients differed from controls in cortical thickness, SBA was performed. The cortical thickness measure was obtained from T1-weighted images for each participant using FreeSurfer (version 5.3; http://surfer.nmr.mgh.harvard.edu) (Dale et al., 1999; Fischl et al., 1999; Fischl and Dale, 2000). The processing pipeline consisted of affine registration of the T1-weighted volume to Talairach space, skull stripping, followed by WM segmentation and tessellation of the gray/white matter boundary. At each step, visual inspection and manual correction of topological errors was performed. Following cortical reconstruction, brains were inflated, averaged across participants, and smoothed using a $10 \mathrm{~mm}$ FWHM Gaussian kernel. The cortical surface was then parcellated into 34 distinct regions (Desikan-Killiany atlas) for each hemisphere from which mean cortical thickness was derived (Desikan et al., 2006). A direct measure of cortical thickness was calculated by FreeSurfer using the distance $(\mathrm{mm})$ between the pial and gray-white matter boundary at each vertex. 


\section{Resting-state functional connectivity}

All resting-state $\mathrm{fMRI}$ data were preprocessed using SPM8. Resting-state fMRI preprocessing steps included slice timing correction, motion correction, coregistration of the anatomical image to the mean functional image, segmentation of the anatomical image into GM, WM, and CSF, and normalization of anatomical and functional images to the standard MNI brain template. Normalized images were smoothed with an $8 \mathrm{~mm}$ isotropic FWHM Gaussian kernel. Single-subject connectivity analysis was performed with the Conn toolbox (Whitfield-Gabrieli and Nieto-Castanon, 2012). Resting-state fMRI was bandpass filtered $(0.008$ to $0.09 \mathrm{~Hz})$, signal associated with the six motion parameters and those extracted from four WM and three CSF seed regions were removed. We performed a seed-based, voxelwise analysis using three regions of interest. All seeds were $8 \mathrm{~mm}$ spheres generated in the MarsBar toolbox (http://marsbar.sourceforge.net). Two of the three seed regions were created using MNI coordinates from peak voxels obtained from the VBM analysis showing significant negative correlations between GMV and migraine pain intensity (past month). These seed regions were all lateralized to the left $(L)$ hemisphere and included the PCC $(-8,-46,27)$ and alNS $(-36,14,-23)$. In addition, we also chose the aMCC $(-3$, $29,20)$ as a seed for the connectivity analysis based on the finding of significant group differences in cortical thickness obtained from the SBA results. We chose these seeds given our hypotheses that intrinsic connectivity within the DMN (i.e., PCC) would be altered due to enhanced engagement of the functionally competing salience network (SN) (i.e., alNS and aMCC) (Raichle et al., 2001; Seeley et al., 2007; Taylor et al., 2009; Napadow et al., 2010) resulting in migraine patients showing impaired ability to disengage attention from ongoing pain, as evidenced by higher pain catastrophizing scores compared with controls.

\section{Statistical analysis}

\section{Behavioral analyses}

One-way ANOVAs were conducted to determine whether groups differed in age, mood disturbance (POMS), pain catastrophizing (PCS), pain-related characteristics (i.e., quality and intensity), and associated disability (SFMPQ, MIDAS). In addition, Chi-square tests ( $\chi^{2}$ statistic) were performed on frequency measures of handedness, gender, and education level. A repeated-measures ANOVA was also performed to determine if patients' migraine pain intensity ratings differed prior to and following scanning.

Voxel-based morphometry and surface-based analyses All voxel-based analyses were performed using SPM8. Voxelwise comparisons in GMV between groups were performed using a GLM analysis with group specified as the fixed factor, and age and mean centered total intracranial volume (calculated by summing each participant's GM, WM, and CSF volumes) entered as nuisance variables. For the surface-based analyses, group comparisons for cortical thickness were conducted separately for each hemisphere using FreeSurfer's Query, Design, Estimate, Contrast (QDEC) graphical interface (version 1.4).
Cortical thickness analysis for the between-group comparisons was performed using a GLM model with group specified as the fixed factor and age designated as a nuisance variable. Results for each analysis were projected onto the averaged brain map using QDEC. For both the VBM and SBA analyses, we applied an initial cluster forming significance threshold of $p \leq 0.005$ and a cluster extent of 100. Correction for multiple comparisons was performed using random-field-theory-based significant clusters at $p<0.05$.

Functional connectivity analysis Group-level analyses were performed on each seed using SPM8 to compare differences in functional connectivity in patients and controls, while controlling for age. Significance thresholds for all analyses were set to a $p \leq 0.005$ (minimum initial cluster extent $=100$ voxels) and cluster-level corrected for multiple comparisons. To determine if group differences in RS-FC varied depending upon the degree of pain catastrophizing, an additional GLM analysis was conducted specifying PCS scores (mean centered) as a covariate of interest. Separate GLM analyses were also performed in patients to determine if changes in RS-FC were related to migraine disease characteristics (mean centered). For these analyses, disease duration, attack frequency (past month), and migraine pain intensity (past month) were entered as covariates into the model.

\section{Results}

\section{Behavioral and clinical measures}

Descriptive and inferential statistics for group demographics and behavioral measures are presented in Table 1. No significant group differences were observed for age, gender, handedness, or education level. As expected, patients had significantly higher PCS scores than healthy controls. Patients also had significantly higher total POMS scores, indicating greater overall mood disturbance, and scored higher on the SFMPQ and MIDAS, reflecting greater pain intensity and associated headacherelated disability relative to controls.

In the patient group, mean (SD) score for the GHQ-60 was $24.12( \pm 10.44)$. Patients reported an average disease duration of $12.53( \pm 8.41)$ years, and an attack frequency of $11.65 \mathrm{~d}( \pm 10.07)$ over the past month, $76.12 \mathrm{~d}( \pm 60.70)$ over the past 6 months, and $133.82 \mathrm{~d}( \pm 106.11)$ over the past year. For migraine pain intensity, patients reported an average of $3.65( \pm 3.00)$ for the past $24 \mathrm{~h}, 4.92( \pm 2.33)$ for the past week, and $5.72( \pm 2.16)$ for the past month. Although no patients reported having migraine headaches elicited by scanning per se, four of the 17 patients did report having a migraine headache just prior to the scan session, which lasted for the duration of the scan. Migraine pain intensity assessed just prior to scanning was $2.93( \pm 2.95)$ and $3.77( \pm 2.98)$ at the end of the scan session. A repeated-measures ANOVA revealed no significant difference between prescan and postscan migraine pain intensity ratings $(F=3.41, p=0.086)$. 
Table 1. Descriptive and inferential statistics for demographic and behavioral measures in migraine patients and healthy controls

\begin{tabular}{|c|c|c|c|c|}
\hline Variable & Healthy controls & Migraine patients & Test statistic & $p$ \\
\hline$\overline{\text { Gender (F/M) }}{ }^{a}$ & $14 / 4$ & $13 / 4$ & 0.008 & 0.930 \\
\hline Handedness (R/L) ${ }^{a}$ & $16 / 2$ & $16 / 1$ & 0.305 & 0.581 \\
\hline Age (years) & $38.89 \pm 11.25$ & $41.71 \pm 12.20$ & 0.505 & 0.482 \\
\hline Education level $^{a}$ & & & 0.369 & 0.985 \\
\hline High school & $1(5.6 \%)$ & $1(5.9 \%)$ & - & - \\
\hline Some college & $2(11.1 \%)$ & $2(11.8 \%)$ & - & - \\
\hline Bachelors & $8(44.4 \%)$ & $6(35.3 \%)$ & - & - \\
\hline Masters & $4(22.2 \%)$ & $5(29.4 \%)$ & - & - \\
\hline Doctorate & $3(16.7 \%)$ & $3(17.6 \%)$ & - & - \\
\hline POMS (Total) & $37.11 \pm 10.27$ & $59.18 \pm 16.79$ & 22.28 & $<0.001$ \\
\hline Depress/Deject & $15.61 \pm 1.14$ & $17.35 \pm 2.50$ & 7.17 & 0.011 \\
\hline Tension/Anxiety & $12.94 \pm 2.21$ & $16.59 \pm 4.18$ & 10.55 & 0.003 \\
\hline Anger/Hostility & $12.72 \pm 1.45$ & $13.00 \pm 1.87$ & 0.243 & 0.625 \\
\hline Confusion/Bewilderment & $10.50 \pm 1.79$ & $13.00 \pm 3.89$ & 6.082 & 0.019 \\
\hline Fatigue/Inertia & $9.56 \pm 2.62$ & $14.82 \pm 4.90$ & 15.984 & $<0.001$ \\
\hline Vigor/Activity & $24.22 \pm 6.91$ & $15.59 \pm 4.89$ & 18.025 & $<0.001$ \\
\hline PCS (Total) & $7.94 \pm 9.43$ & $18.47 \pm 8.62$ & 11.835 & 0.002 \\
\hline MIDAS (Total) & $0.56 \pm 1.20$ & $71.71 \pm 73.89$ & 16.716 & $<0.001$ \\
\hline SFMPQ (Total) & $0.00 \pm 0.00$ & $7.53 \pm 7.60$ & 17.697 & $<0.001$ \\
\hline
\end{tabular}

Descriptive statistical values are represented as percentages (\%) or means \pm SD for the healthy control and migraine patient groups. In cases where inferential statistics were also performed, the test statistic and corresponding $p$ value for the one-way ANOVA ( $F$ statistic) or Pearson's chi-square test $\left(\chi^{2}\right.$ statistic; indicated by ${ }^{a}$ ) are shown. The $p$ values for test statistics that reached significance are bolded. Abbreviations are as defined in the text.

M, Males; F, females.

\section{Group comparisons between patients and controls for structural measures}

For the VBM analysis, significant group differences in regional GMV were observed for the $L$ hippocampus with patients having greater GMV compared with controls $(p=$ 0.011; Table 2, Fig. 1A). For the SBA analysis, migraineurs showed significant reductions in cortical thickness in the $\mathrm{L}$ aMCC relative to healthy controls (Table 2, Fig. 2A).

\section{Association between structural measures and pain catastrophizing}

There were significant group $\times$ catastrophizing interactions in several regions for both VBM and SBA in which patients showed negative correlations and controls showed positive correlations with pain catastrophizing. These results, as well as partial correlations for each group, are shown in Table 2. For GMV, there were significant group $\times$ catastrophizing interactions in the $L$ primary somatosensory cortex (S1), L mPFC, and L aMCC (Fig. 1B). For cortical thickness, significant interactions were found in the L DLPFC, $L$ middle temporal gyrus (MTG), and right (R) inferior frontal gyrus (IFG) (Fig. 2B).

\section{Association between structural measures and migraine disease variables}

For the patient group, significant relationships emerged between structural measures and migraine disease variables (Table 2). Analyses performed between VBM and SBA and disease severity measures yielded predominantly negative correlations in pain-related, affective- motivational, and visuospatial brain areas. For example, disease duration correlated negatively with GMV (Fig. 1C) for the bilateral posterior insula (pINS) and L IFG, and with cortical thickness for the bilateral DLPFC (Fig. 2C). Patients' attack frequency scores also negatively correlated with GMV (Fig. 1D) and cortical thickness in the lingual gyrus and R S1 (Fig. 2D). Migraine pain intensity negatively correlated with GMV in the L alNS and L PCC (Fig. $1 E$ ) and cortical thickness in the L PCC, L IFG, L fusiform, $\mathrm{R} \mathrm{mPFC}$, and $\mathrm{R}$ lingual gyrus (Fig. 2E).

\section{Resting-state functional connectivity analysis}

Whole-brain overlay maps for each of the three seed regions are displayed in Figure 3 to show the brain networks represented in each analysis. Overall, the connectivity pattern for the PCC seed matched the DMN. The alNS and aMCC seed connectivity patterns were consistent with the SN. Statistical tests assessing group differences in connectivity patterns are described below.

\section{Group differences in resting-state functional connectivity}

Compared with controls, patients showed increased connectivity between the alNS seed and the $L$ cuneus and between the aMCC seed and the R lingual gyrus (Table 3 , Fig. 4A). For the PCC seed, patients relative to controls showed reduced RS-FC with the bilateral DLPFC, bilateral S1, R mPFC, R PPC, R IFG, and R inferior temporal gyrus (ITG) (Table 3, Fig. 4B).

\section{Relationship between pain catastrophizing and functional connectivity}

Results for the group $\times$ catastrophizing interactions and partial correlations are displayed in Table 3. Partial correlation analysis revealed that in patients, catastrophizing correlated with RS-FC between the alNS seed and the L 


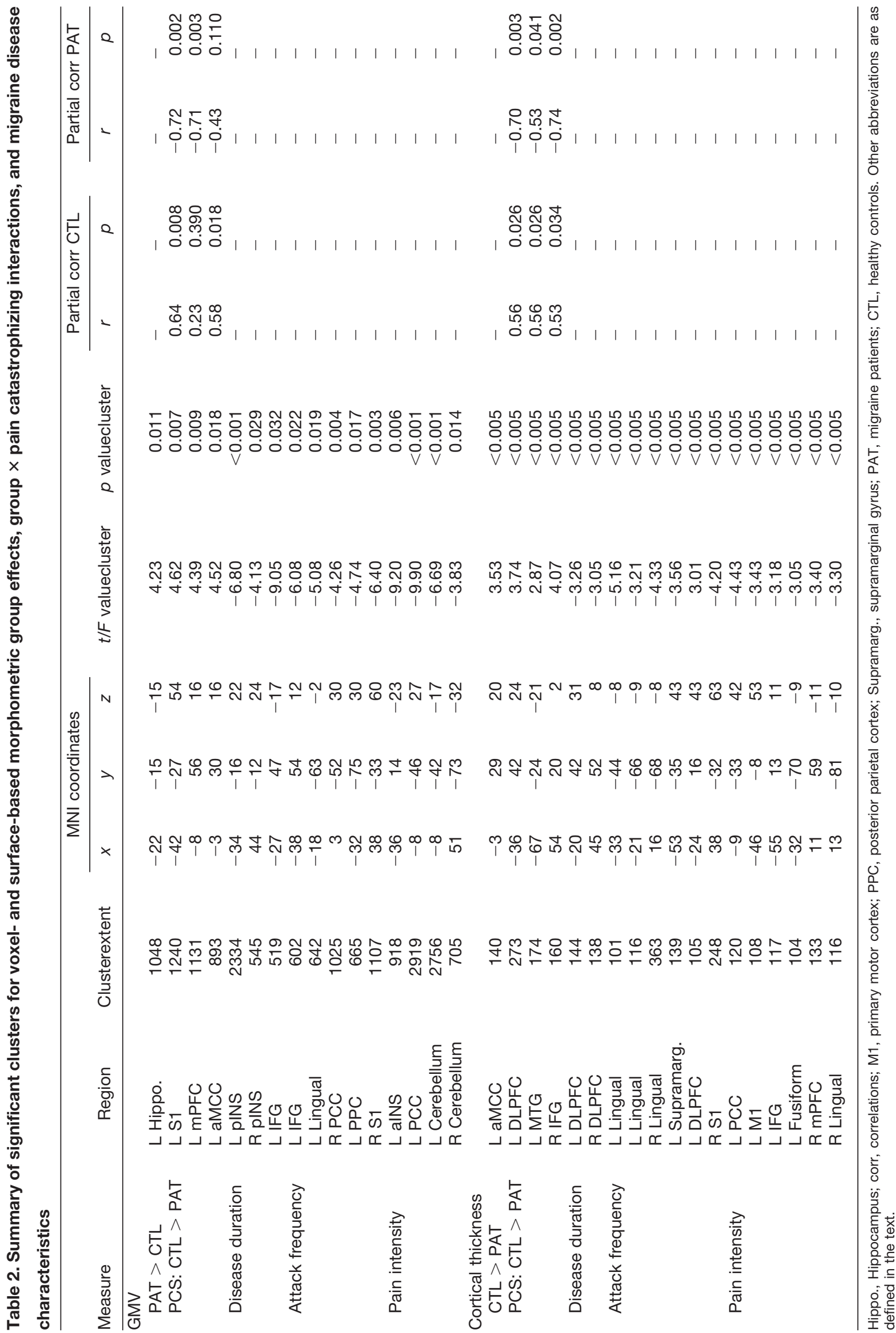




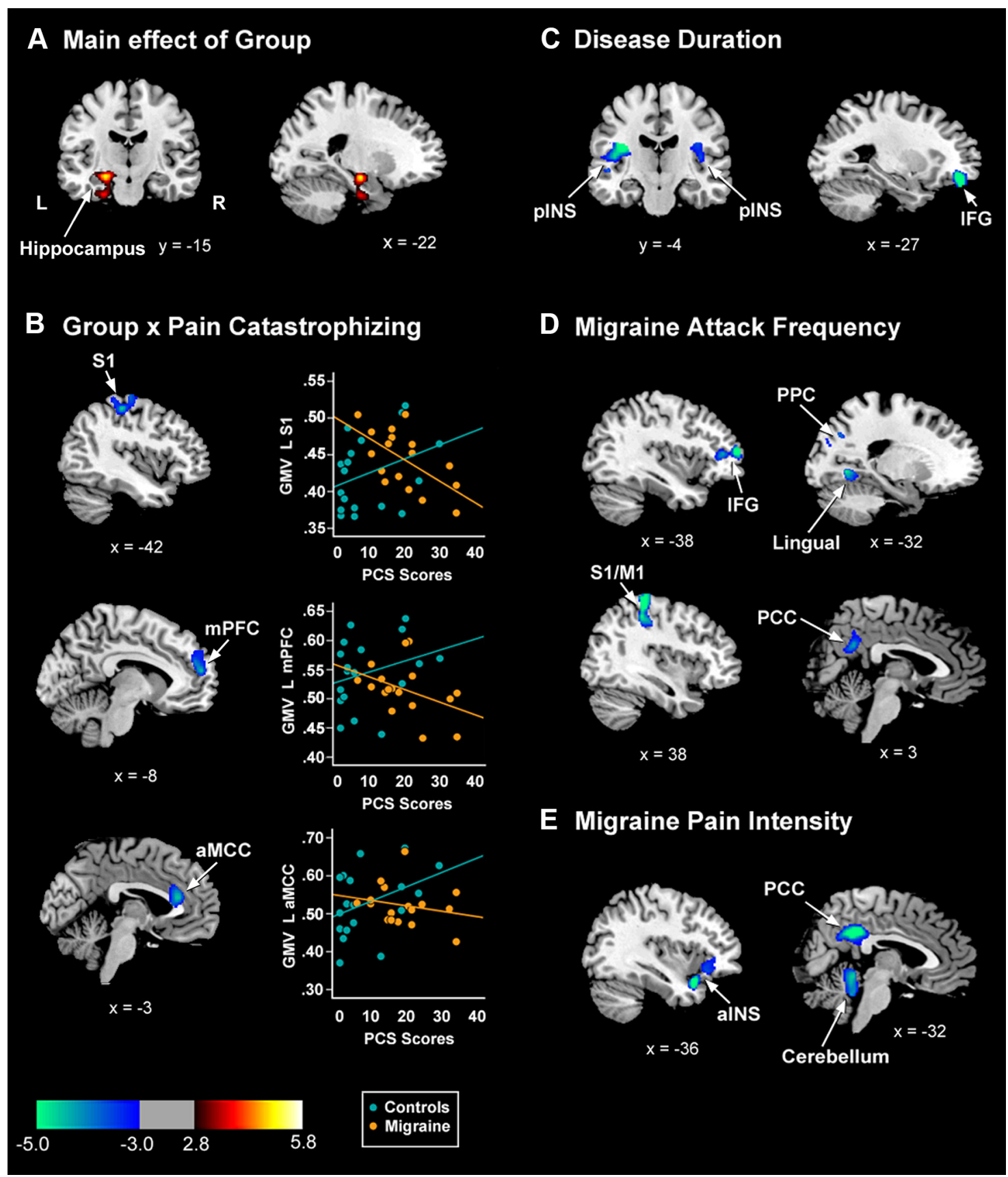

Figure 1. Statistical maps for the voxel-based morphometric analysis overlaid onto the averaged ch2bet brain template in MRlcron. $\boldsymbol{A}$, Patients showed significant increased GMV in the left hippocampus, which extended into the parahippocampal gyrus, compared with controls. L, Left hemisphere; $R$, right hemisphere. $\boldsymbol{B}$, Cortical areas showing significant group $\times$ pain catastrophizing interactions for GMV and corresponding scatter plots showing correlations between GMV and catastrophizing in migraine patients (orange circles) and healthy controls (blue circles). $\boldsymbol{C}-\boldsymbol{E}$, Regions showing significant reductions in GMV that correlated with longer disease durations $(\boldsymbol{C})$, greater attack frequency $(\boldsymbol{D})$, and migraine pain intensity in patients $(\boldsymbol{E})$.

hippocampus, LSMA, and the bilateral thalamus (Fig. 4C). For the PCC seed, catastrophizing correlated with increased RS-FC with the bilateral DLPFC in patients (Fig. $4 D$ ), whereas in controls, catastrophizing negatively correlated with PCC and R DLPFC coupling, but not with the L DLPFC (Fig. 4D). Note that these DLPFC clusters were slightly more anterior and medial (deeper in the sulcus) than those identified in the above group analysis with PCC connectivity.

Relationship between migraine disease variables and functional connectivity

Results of the RS-FC analyses for the migraine-related disease variables are shown in Table 4. Disease dura- 


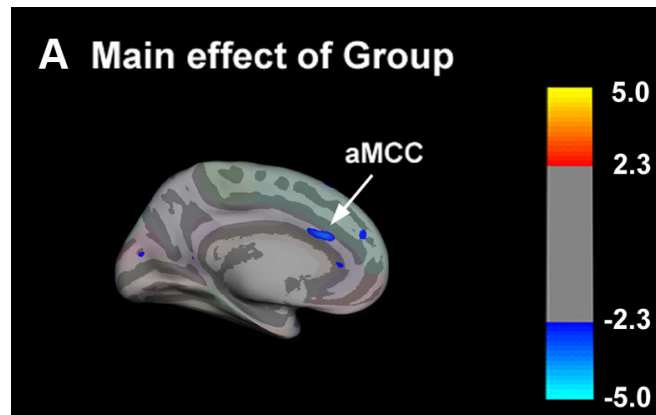

B Group x Pain Catastrophizing
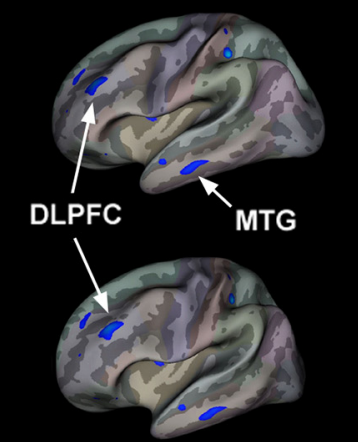

Controls - Migraine
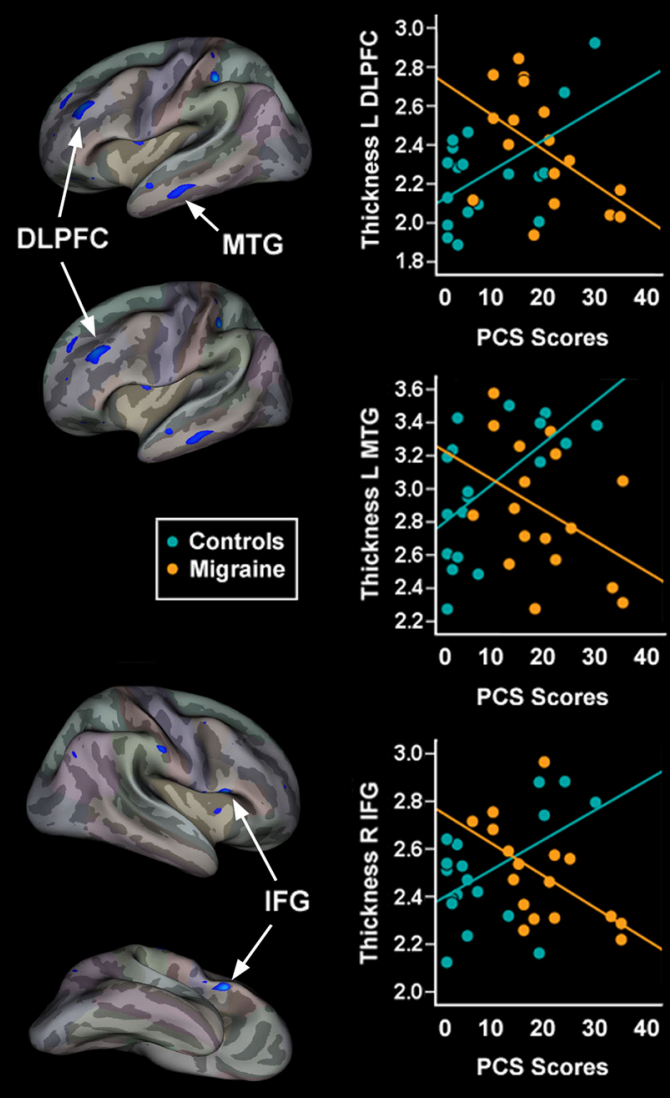

\section{Disease Duration}
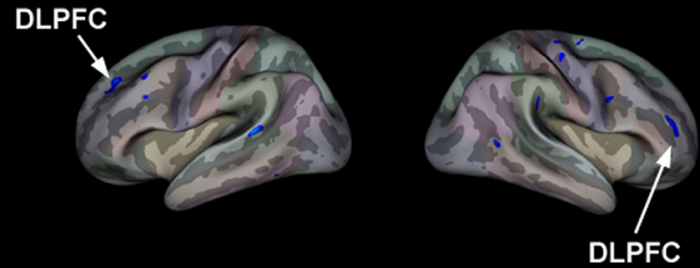

D Migraine Attack Frequency
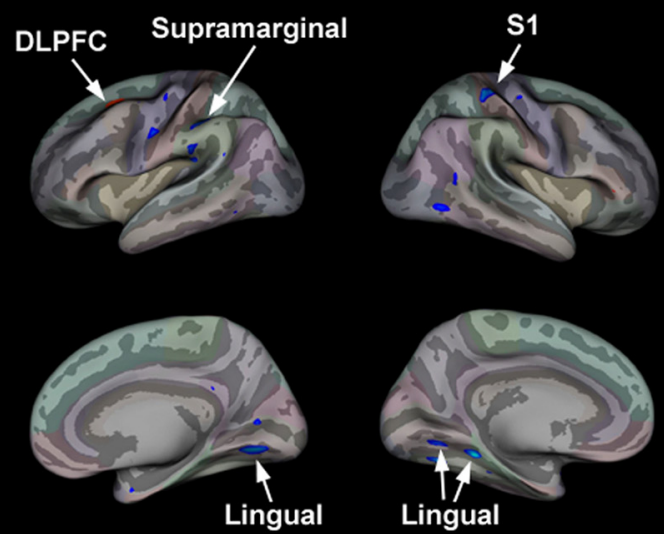

E Migraine Pain Intensity
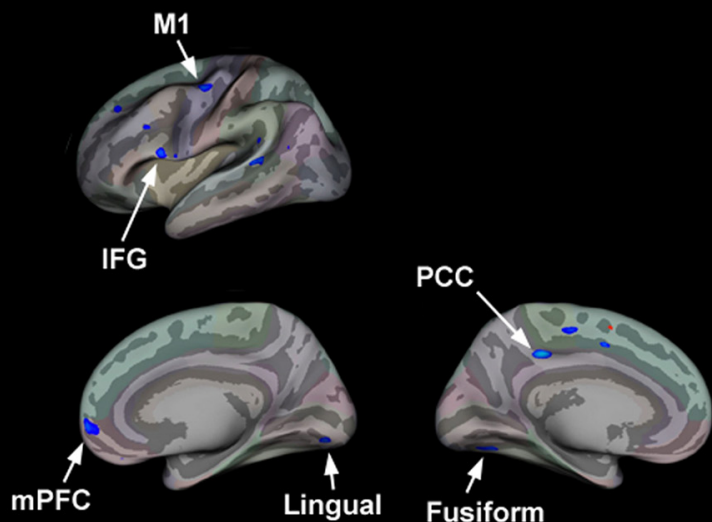

Figure 2. Statistical maps for the surface-based analysis rendered onto the inflated averaged brain template using Freesurfer's QDEC graphical user interface software. $\boldsymbol{A}$, Group differences in cortical thickness were found; migraine patients showed significant reductions in cortical thickness in the left aMCC compared with healthy controls. $\boldsymbol{B}$, Cortical areas showing significant group $\times$ pain catastrophizing interactions for cortical thickness measures and corresponding scatter plots displaying correlations between cortical thickness and catastrophizing in migraine patients (orange circles) and healthy controls (blue circles). $\boldsymbol{C}-\boldsymbol{E}$, Cortical areas showing significant cortical thinning (blue) and thickening (red) in migraine patients that were associated with longer disease durations (C), greater migraine attack frequency $(\boldsymbol{D})$, and migraine pain intensity in patients $(\boldsymbol{E})$.

tion positively correlated with RS-FC between the DMN-PCC seed and the R pons, whereas alNS and aMCC seeds belonging to the $\mathrm{SN}$ negatively correlated with DMN nodes. For attack frequency, significant negative correlations between the DMN-PCC seed and the
PPC were found. For migraine pain intensity, patients had significant positive correlations between the DMNPCC seed and nodes within the sensorimotor and visuospatial networks, including the L S1 and R secondary visual cortex (V2). 
PCC

$(-8,-46,27)$
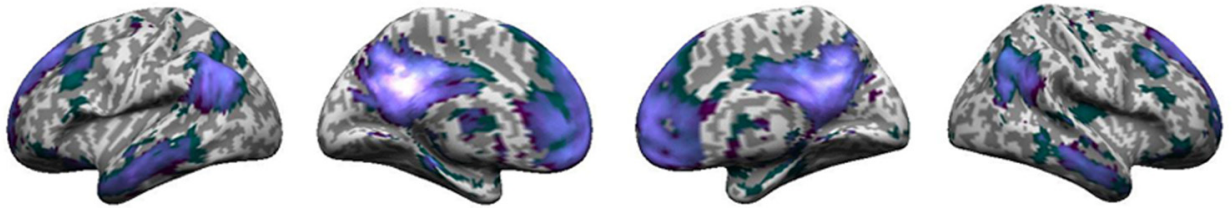

alNS

$(-36,14,-23)$
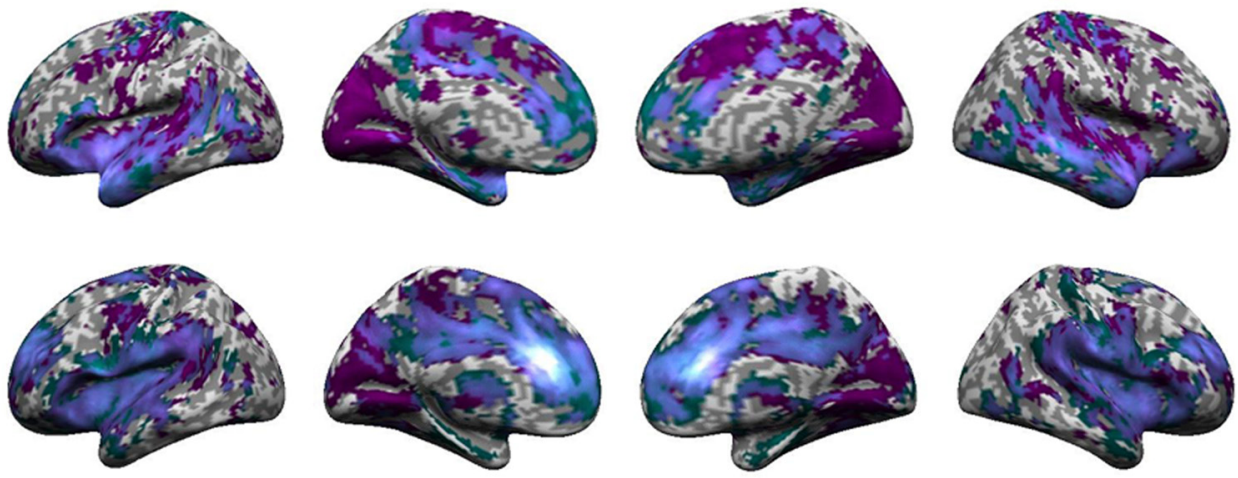

Healthy Controls

Migraine Patients

Figure 3. Whole-brain overlay maps for patients and controls for the left PCC, left alNS, and aMCC seed regions, rendered onto inflated brains in SPM8. Teal represents RS-FC for healthy controls and purple represents the same maps in migraine patients. Light violet represents areas showing overlap in RS-FC in controls and patients. Images are thresholded at $\mathrm{T}=4.5$ (cluster extent $=25$ ) for visualization purposes. The PCC seed showed a connectivity map consistent with the DMN, whereas the alNS and aMCC seeds connectivity patterns were consistent with the SN.

\section{Discussion}

We hypothesized that migraine patients would show concomitant structural and functional abnormalities in painrelated brain regions and that these structural-functional changes would be associated with higher levels of pain catastrophizing and measures of disease chronicity and symptom severity. Our VBM analysis showed that migraineurs had significantly larger GMV in the $L$ hippocampus compared with controls. Results from our SBA analysis revealed significant reductions in cortical thickness in the $L$ aMCC. Pain intensity in patients negatively correlated with GM in multiple areas, including the PCC and alNS. In addition, pain catastrophizing in patients correlated with reduced cortical GM in brain areas involved in processing the attentional, sensory, and affective aspects of pain, including the DLPFC, MPFC, IFG, MTG, and S1, with many of these same areas also showing disrupted RS-FC. The majority of these structural and functional brain abnormalities were negatively correlated with measures of disease duration, attack frequency, and migraine pain intensity, suggesting they may be a consequence of repeated, painful attacks over time.

A major finding in the present study was the significant GMV increase in the $L$ hippocampus in migraineurs compared with controls. This finding is consistent with morphometric studies conducted in chronic pain patients, such as low-frequency migraine, chronic pelvic pain, and burning mouth syndrome (Schweinhardt et al., 2008; Maleki et al., 2013; Khan et al., 2014). The hippocampus is involved in learning and memory, decision making, regulation of the stress response, and affective processing. Although the role of the hippocampus in pain processing has received little attention until recently, previous animal studies using electrophysiological and neurohistochemical techniques provide strong support for hippocampal involvement in pain-related functions (Archer and Roth, 1997; Zheng and Khanna, 1999; Wei et al., 2000; Carter et al., 2011). Moreover, neuroimaging studies utilizing evoked pain paradigms in both healthy controls and irritable bowel syndrome (IBS) patients have demonstrated hippocampal activation in response to noxious stimuli, particularly when the stimulation is of an unpredictable nature (Ploghaus et al., 2000, 2001; WilderSmith et al., 2004). Although speculative, the hippocampal GMV increase in patients observed here may be indicative of activity-dependent neuroplastic changes resulting from chronic nociceptive signaling originating from trigeminal sensory afferents. Thus, neuroplastic changes, including neurogenesis, unmasking of silent synapses, morphological restructuring of synaptic connections, and/or dendritic arborization, may be related to LTP-like processes occurring within hippocampal neuronal ensembles, a mechanism by which memory for pain may be encoded (Bruel-Jungerman et al., 2006; Sandkuhler, 2007).

Our SBA analysis revealed significant cortical thinning in the $\mathrm{L}$ aMCC in patients compared with controls. The aMCC is involved in processing the affective-motivational dimensions of pain, as well as pain-related anticipatory, attentional, and cognitive inhibitory control 


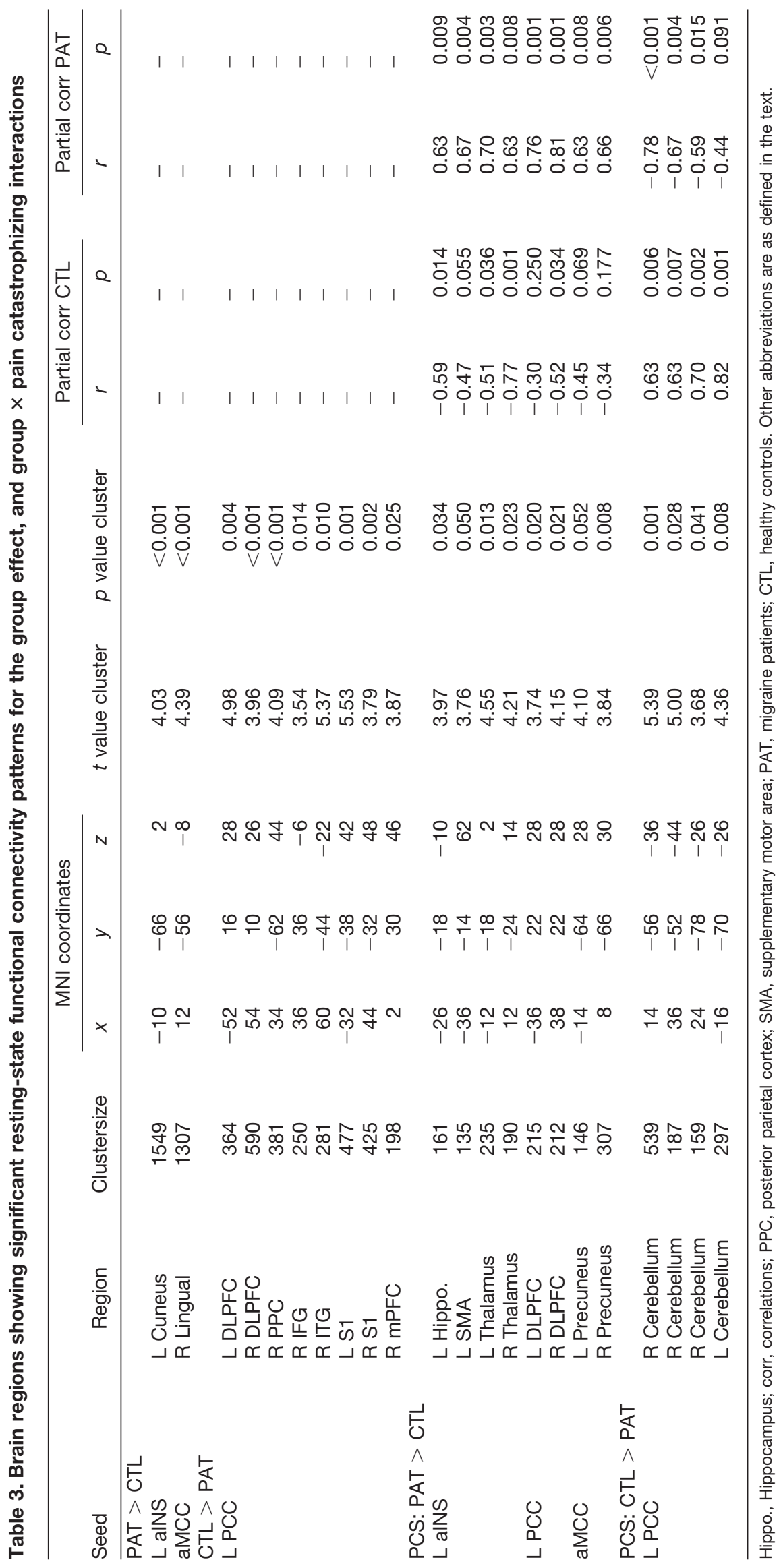


Main effect of Group: PAT > CTL

A
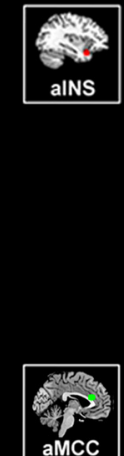

aMcc

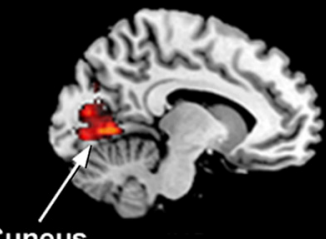

Cuneus

$x=-10$

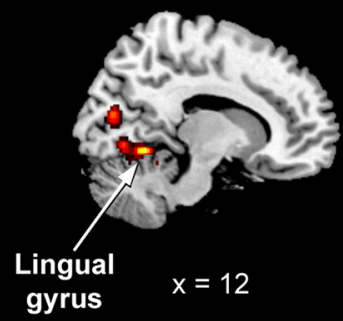

B

DLPFC
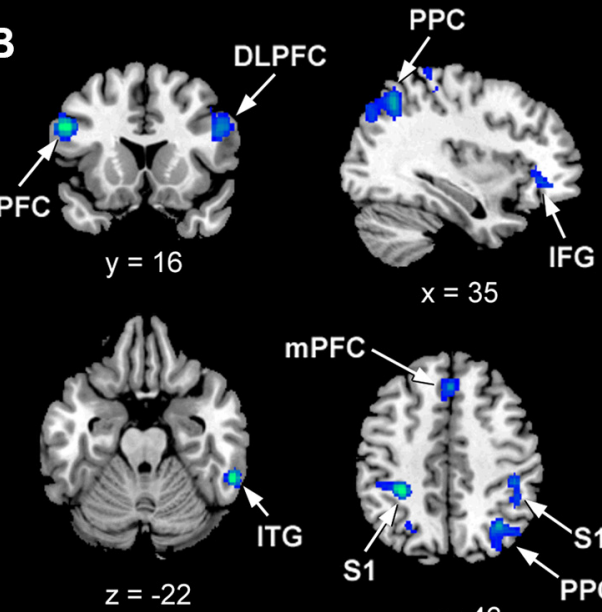

$z=-22$

mPFC

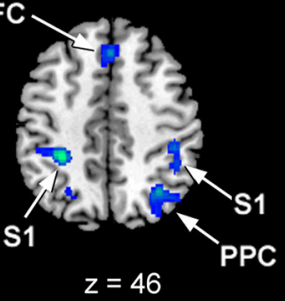

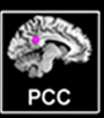

PCC

\section{Pain Catastrophizing: PAT > CTL}

C

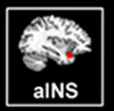

Hippocampus
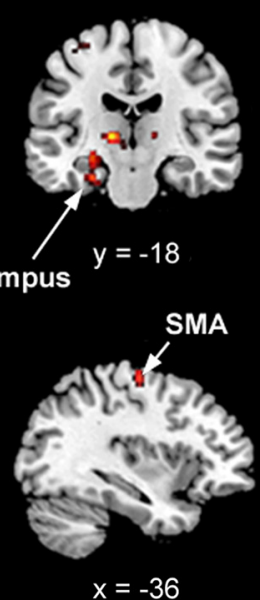

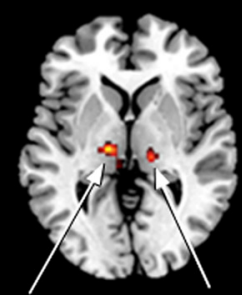

Thalamus Thalamus $z=2$
D
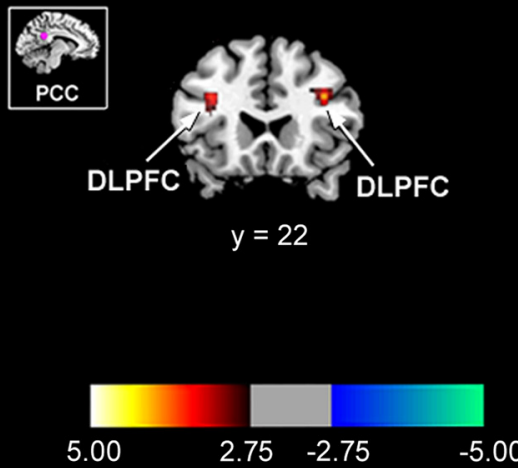

Figure 4. Group differences in RS-FC for the alNS and aMCC seeds (SN) and PCC seed (DMN) overlaid onto the average ch2bet brain template in MRIcron. $\boldsymbol{A}$, Patients showed significant enhancement in alNS and aMCC connectivity with the $L$ cuneus and $R$ lingual gyrus, respectively, and $\boldsymbol{B}$, reduced connectivity between the PCC seed and bilateral DLPFC, S1, R PPC, R IFG, R ITG, and R mPFC. $\boldsymbol{C}, \boldsymbol{D}, \mathrm{RS}-\mathrm{FC}$ group differences associated with pain catastrophizing for the alNS and PCC seeds. $\boldsymbol{C}$, Patients high in catastrophizing showed enhanced RS-FC between the alNS and the L hippocampus, L SMA, and bilateral thalami. $\boldsymbol{D}$, Significant increases in RS-FC were also identified between the PCC and the bilateral DLPFC in patients with greater pain catastrophizing scores. PAT, Patients; CTL, controls.

functions (Shackman et al., 2011). Although previous VBM studies have reported GMV reductions in the aMCC and adjacent areas within the rostral cingulate in both migraineurs and chronic tension headache patients (Schmidt-Wilcke et al., 2005, 2008; Rocca et al., 2006; Kim et al., 2008), only one study has identified cortical volume differences in this region using SBA (Maleki et al., 2012) and no study has reported differences in cortical thickness. Our SBA results demonstrating reduced corti- cal thickness in the aMCC indicate that migraineurs show significant structural abnormalities in an area involved in processing the affective-motivational aspects of pain.

According to the attentional model, pain catastrophizing reflects a propensity to attend to painful events or experiences, whether real or imagined. This inability to shift attentional focus away from pain, in turn, leads to increased pain perception and sensitivity (Crombez et al., 1998; Sullivan et al., 2001; Goubert et al., 2004; Van 
Table 4. Summary of significant correlations between whole-brain resting-state functional connectivity and migraine disease characteristics

\begin{tabular}{|c|c|c|c|c|c|c|c|c|c|}
\hline \multirow[b]{2}{*}{ Diseasecharacteristics } & \multirow[b]{2}{*}{ Seed } & \multirow[b]{2}{*}{ Region } & \multirow[b]{2}{*}{ Clustersize } & \multicolumn{3}{|c|}{ MNI coordinates } & \multirow[b]{2}{*}{$t$ value cluster } & \multirow[b]{2}{*}{$p$ value cluster } & \multirow[b]{2}{*}{$+/-\operatorname{cor}$} \\
\hline & & & & $x$ & $y$ & $z$ & & & \\
\hline \multirow[t]{7}{*}{ Disease duration } & L alNS & R Caudate & 133 & 6 & 14 & 6 & 4.12 & 0.036 & - \\
\hline & & L PPC & 488 & -52 & -56 & 50 & 6.32 & $<0.001$ & - \\
\hline & & L MTG & 213 & -48 & -24 & -10 & 5.58 & 0.010 & - \\
\hline & & L SFG & 139 & -16 & 38 & 58 & 5.66 & 0.032 & - \\
\hline & & L mPFC & 1578 & -2 & 42 & -14 & 5.31 & $<0.001$ & - \\
\hline & L PCC & R Pons & 181 & 4 & -30 & -38 & 6.63 & 0.014 & + \\
\hline & aMCC & $\mathrm{R}$ mPFC & 133 & 6 & 34 & -16 & 4.95 & 0.048 & - \\
\hline \multirow[t]{4}{*}{ Attack frequency } & $\mathrm{L}$ alNS & L ITG & 131 & -34 & 14 & -32 & 5.82 & 0.038 & - \\
\hline & & L Hippocampus & 121 & -32 & -44 & 2 & 5.26 & 0.045 & + \\
\hline & L PCC & L PPC & 136 & 0 & -40 & 66 & 5.93 & 0.028 & - \\
\hline & aMCC & L MTG & 148 & -52 & -4 & -34 & 5.27 & 0.038 & - \\
\hline \multirow{4}{*}{ Pain intensity } & L PCC & R V2 & 105 & 54 & -68 & 22 & 4.21 & 0.049 & + \\
\hline & & R Fornix & 170 & 20 & -40 & 26 & 6.24 & 0.016 & - \\
\hline & & L PPC & 399 & -36 & -38 & 30 & 7.20 & 0.001 & + \\
\hline & aMCC & $\mathrm{R}$ alNS & 269 & 32 & 12 & 10 & 9.19 & 0.038 & + \\
\hline
\end{tabular}

PPC; Posterior parietal cortex; SFG, superior frontal gyrus; STG, superior temporal gyrus. +/- corr denotes positive or negative correlation. Other abbreviations are as defined in the text.

Damme et al., 2004). To our knowledge, no study to date has examined the association between pain catastrophizing and structural GM abnormalities in migraine patients. Here, we show a strong association between catastrophizing and gray matter reductions in S1, mPFC, DLPFC, MTG, and IFG. These findings are in accord with functional and morphometric studies showing a strong relationship between catastrophizing and abnormalities in similar regions in IBS and fibromyalgia patients (Gracely et al., 2004; Blankstein et al., 2010). Taken together, our findings indicate that higher levels of catastrophizing in patients are linked with GM reductions in areas critically involved in the sensory-discriminative aspects, as well as the top-down, cognitive inhibitory control of pain. We suggest that these cortical alterations may lead to increased pain transmission and an inability to efficiently disengage attention from pain in migraine patients, which would account for some of the cognitive impairments reported in the literature (Martins de Araujo et al., 2012).

We found significant relationships between structural GM changes in areas involved in pain processing, cognitive inhibitory control, and visuospatial functions and migraine disease variables. GMV in the bilateral pINS and cortical thickness in the bilateral DLPFC correlated with longer disease duration, consistent with previous findings in migraine and chronic tension type headache (SchmidtWilcke et al., 2005; Rocca et al., 2006; Kim et al., 2008; Schmitz et al., 2008; Valfre et al., 2008). Attack frequency was associated with greater GMV and cortical thickness in regions within the frontal, parietal, and occipitaltemporal regions. Many of these regions serve in processing attention and pain modulation, as well as processing visual information. We also observed strong associations between migraine pain intensity and lower GM in many of the same areas showing morphological abnormalities related to disease duration and attack frequency (i.e., PCC, IFG, lingual gyrus, and S1). Collectively, the observed structural abnormalities in pain-related and visuospatial brain areas may underlie the pathophysiology of migraine symptoms (e.g., blurred vision, sensitivity to light, visual disturbances) and, therefore, may serve as important indicators of disease severity.

Recent studies employing RS-FC have provided evidence of anatomically segregated and functionally dissociable intrinsic brain networks. These networks include the well known DMN and the central executive network (CEN), among others (Raichle et al., 2001; Seeley et al., 2007; Buckner et al., 2008; Spreng et al., 2009). It has recently been proposed that these spatially segregated networks play a critical role in internally and externally guided cognition, respectively. The DMN is said to be active during rest and has been termed a "task negative network", since it shows reliable deactivation during cognitively demanding tasks (Buckner et al., 2008; Spreng et al., 2013). Conversely, the CEN, which is thought to play an important role in executive functions, guiding externally driven goal-directed attentional focus and cognition, is referred to as a "task positive network", since it is primarily activated during tasks requiring allocation of attentional resources and higher-order cognition (Seeley et al., 2007; Dosenbach et al., 2008). This network includes, but is not limited to, areas such as the DLPFC and PPC. A third network, known as the SN, which includes core nodes aMCC and bilateral alNS, may be involved in modulating the activity within these two networks by regulating the switching between internal or externally generated cognitive demands of the functionally competing DMN and CEN networks, depending upon the saliency ascribed (Seeley et al., 2007; Taylor et al., 2009; Sridharan et al., 2008; Goulden et al., 2014). Thus, SN coupling with $\mathrm{DMN}$ may promote internally guided mentation by guarding against disruptive or competing stimuli arising from external sources and simultaneously dampening the CEN. Similarly, decoupling of the DMN with the SN may promote functional engagement with the CEN and facilitate 
the shifting of focus toward salient external events that demand immediate attention.

To examine how structural brain changes were related to functional connectivity changes in patients, we used areas identified in the structural analyses as seed regions in our RS-FC analyses, with a focus on DMN and SN, since those networks have been most reliably shown to have altered connectivity in chronic pain conditions. Overall, patients showed disrupted DMN and SN connectivity patterns compared with healthy controls. Specifically, patients had reduced RS-FC within the DMN (L PCC seed with IFG, ITG, and mPFC) and increased RS-FC of the SN to extrastriate visual areas. Patients also showed decreased connectivity between the DMN and regions of the CEN (bilateral DLPFC, PPC), as well as a somatosensory network (bilateral S1). These findings strongly indicate atypical connectivity patterns in patients associated with vigilance to visual stimuli and engagement of cognitive and somatosensory networks at baseline, which may reflect a general hypervigilance or enhanced attentional focus toward salient events, such as ongoing pain, as well as sensitivity to visual stimuli, which are common triggers for migraine headaches.

Patients also showed altered RS-FC associated with pain catastrophizing and migraine disease characteristics. Patients with high catastrophizing showed greater disruptions in DMN connectivity, namely increased correlation between the PCC-DMN node and the CEN (i.e., bilateral DLPFC). Additionally, in patients, pain catastrophizing correlated with RS-FC between SN nodes to the hippocampus, posterior thalamus, and the bilateral precuneus (nodes of the DMN). These findings provide further support for the notion that migraine patients display enhanced brain activation in cognitive-control inhibitory networks and areas mediating affect-related responses to salient events, likely a result from hypervigilance to their pain, reflected by higher catastrophizing, at the expense of the DMN functioning at rest. Furthermore, disease duration was associated with SN and DMN (mPFC, MTG, and SFG) decoupling. Likewise, attack frequency was also associated with decreased SN-DMN and increased $\mathrm{SN}$-hippocampus connectivity, whereas pain intensity was associated with enhanced coupling between SNCEN nodes (V2, PPC, and alNS). Overall, these findings indicate patients have disrupted RS-FC associated with higher levels of pain catastrophizing and symptom severity, which may reflect impairments in the ability to disengage attention from pain, central pain amplification, and symptom chronification. Future studies will determine whether interventions that reduce pain catastrophizing and symptom severity can reverse some of these aberrant connectivity patterns.

Some limitations should be considered when interpreting the results of the current study. First, our sample of migraine patients was heterogeneous. Although all patients reported a high frequency of attacks $(\geq 8$ headache days/month), four patients reported fewer than 15 headache days per month, which would make them episodic rather than chronic migraine sufferers according to ICHD-II criteria. A second limitation was that we did not control for medication use and the majority of patients in this study were taking prophylactic and/or abortive medications to control their symptoms. For ethical reasons, we did not ask patients to refrain from their typical medication usage patterns and therefore the effect of medication on the present study findings cannot be determined. Third, a potential drawback of RS-FC is that this technique provides no information with regard to the direction or strength of connectivity and thus, interpretation of results obtained using this approach is limited (Buckner et al., 2013). Fourth, our sample of migraine patients was relatively small. Further work is needed in a larger sample of migraine patients to generalize the current findings to a broader clinical population. Finally, the present study was cross-sectional, and therefore we are unable to address whether the morphological and functional brain abnormalities observed here were a cause or an effect of repeated migraine attacks over time. Future studies employing a longitudinal design are needed to address these questions.

\section{Conclusion}

The integration of multimodal techniques represent a promising approach that may lead to a better understanding of the etiological factors underlying migraine pathophysiology. In the present study, we provide evidence that migraine patients have concurrent structural and functional abnormalities in default mode, salience, visuospatial, cognitive control, and pain-related brain networks, which were associated with disease-related symptomology and the degree of pain catastrophizing. Altered structure and functional connectivity of areas critically involved in processing salient events and subserving cognitive inhibitory control functions may reflect neuroplastic brain changes that lead to the impaired ability to self-regulate and disengage attention away from pain, which over time might further reinforce maladaptive behaviors and coping strategies in these patients. Whether the observed functional abnormalities in connectivity result from structural changes that are causal or a consequence of repeated migraine attacks, and how these structural changes are related to altered brain functioning, remains unclear. Future work is needed to determine the extent to which certain interventions are capable of reversing these structural-functional alterations and the impact treatment has on ameliorating migraine-related symptoms.

\section{References}

Archer DP, Roth SH (1997) Pharmacodynamics of thiopentone: nocifensive reflex threshold changes correlate with hippocampal electroencephalography. Br J Anaesth 79:744-749. Medline

Ashburner J (2007) A fast diffeomorphic image registration algorithm. Neuroimage 38:95-113. CrossRef Medline

Ashburner J, Friston KJ (2000) Voxel-based morphometry: the methods. Neuroimage 11:805-821. CrossRef

Ashburner J, Friston KJ (2001) Why voxel-based morphometry should be used. Neuroimage 14:1238-1243. CrossRef Medline

Baliki MN, Geha PY, Apkarian AV, Chialvo DR (2008) Beyond feeling: chronic pain hurts the brain, disrupting the default-mode network dynamics. J Neurosci 28:1398-1403. CrossRef Medline 
Bashir A, Lipton RB, Ashina S, Ashina M (2013) Migraine and structural changes in the brain: a systematic review and meta-analysis. Neurology 81:1260-1268. CrossRef Medline

Blankstein U, Chen J, Diamant NE, Davis KD (2010) Altered brain structure in irritable bowel syndrome: potential contributions of pre-existing and disease-driven factors. Gastroenterology 138: 1783-9. CrossRef Medline

Bruel-Jungerman E, Davis S, Rampon C, Laroche S (2006) Longterm potentiation enhances neurogenesis in the adult dentate gyrus. J Neurosci 26:5888-5893. CrossRef Medline

Buckner RL, Andrews-Hanna JR, Schacter DL (2008) The brain's default network: anatomy, function, and relevance to disease. Ann N Y Acad Sci 1124:1-38. CrossRef Medline

Buckner RL, Krienen FM, Yeo BT (2013) Opportunities and limitations of intrinsic functional connectivity MRI. Nat Neurosci 16: 832-7. CrossRef Medline

Carter JL, Lubahn C, Lorton D, Osredkar T, Der TC, Schaller J, Evelsizer S, Flowers S, Ruff N, Reese B, Bellinger DL (2011) Adjuvant-induced arthritis induces c-Fos chronically in neurons in the hippocampus. J Neuroimmunol 230:85-94. CrossRef Medline

Crombez G, Eccleston C, Baeyens F, Eelen P (1998) When somatic information threatens, catastrophic thinking enhances attentional interference. Pain 75:187-198. Medline

Dale AM, Fischl B, Sereno MI (1999) Cortical surface-based analysis. I. Segmentation and surface reconstruction. Neuroimage 9:179194. CrossRef Medline

DaSilva AFM, Granziera C, Snyder J, Hadjikhani N (2007) Thickening in the somatosensory cortex of patients with migraine. Neurology 69:1990-1995. CrossRef Medline

Datta R, Detre JA, Aguirre GK, Cucchiara B (2011) Absence of changes in cortical thickness in patients with migraine. Cephalalgia 31:1452-1458. CrossRef Medline

Desikan RS, Segonne F, Fischl B, Quinn BT, Dickerson BC, Blacker D, Buckner RL, Dale AM, Maguire RP, Hyman BT, Albert MS, Killiany RJ (2006) An automated labeling system for subdividing the human cerebral cortex on MRI scans into gyral based regions of interest. Neuroimage 31:968-980. CrossRef Medline

Dosenbach NU, Fair DA, Cohen AL, Schlaggar BL, Petersen SE (2008) A dual-networks architecture of top-down control. Trends Cogn Sci 12:99-105. CrossRef Medline

Fischl B, Dale AM (2000) Measuring the thickness of the human cerebral cortex from magnetic resonance images. Proc Natl Acad Sci U S A 97:11050-11055. CrossRef Medline

Fischl B, Sereno MI, Dale AM (1999) Cortical surface-based analysis. II: Inflation, flattening, and a surface-based coordinate system. Neuroimage 9:195-207. CrossRef Medline

Goubert L, Crombez G, Van DS (2004) The role of neuroticism, pain catastrophizing and pain-related fear in vigilance to pain: a structural equations approach. Pain 107:234-241. Medline

Goulden N, Khusnulina A, Davis NJ, Bracewell RM, Bokde AL, McNulty JP, Mullins PG (2014) The salience network is responsible for switching between the default mode network and the central executive network: replication from DCM. Neuroimage 99:180190. CrossRef Medline

Goldberg DP (1978) Manual of the General Health Questionnaire. Windsor, England: NFER Publishing.

Gracely RH, Geisser ME, Giesecke T, Grant MAB, Petzke F, Williams DA, Clauw DJ (2004) Pain catastrophizing and neural responses to pain among persons with fibromyalgia. Brain 127:835-843. CrossRef Medline

Granziera C, DaSilva AF, Snyder J, Tuch DS, Hadjikhani N (2006) Anatomical alterations of the visual motion processing network in migraine with and without aura. PLoS Med 3:1915-21. CrossRef

Headache Classification Subcommittee of the International Headache Society (2004) The International Classification of Headache Disorders. Cephalalgia 24:1-160.

Hinds OP, Rajendran N, Polimeni JR, Augustinack JC, Wiggins G, Wald LL, Diana RH, Potthast A, Schwartz EL, Fischl B (2008) Accurate prediction of $\mathrm{V} 1$ location from cortical folds in a surface coordinate system. Neuroimage 39:1585-1599. CrossRef Medline
Holroyd KA, Drew JB, Cottrell CK, Romanek KM, Heh V (2007) Impaired functioning and quality of life in severe migraine: the role of catastrophizing and associated symptoms. Cephalalgia 27: 1156-1165. CrossRef Medline

Khan SA, Keaser ML, Meiller TF, Seminowicz DA (2014) Altered structure and function in the hippocampus and medial prefrontal cortex in patients with burning mouth syndrome. Pain 155:1472-80 CrossRef Medline

Kim JH, Suh SI, Seol HY, Oh K, Seo WK, Yu SW, Park KW, Koh SB (2008) Regional grey matter changes in patients with migraine: a voxel-based morphometry study. Cephalalgia 28:598-604. CrossRef Medline

Lantéri-Minet M, Radat F, Ch, tard MH, Lucas C (2005) Anxiety and depression associated with migraine: influence on migraine subjects' disability and quality of life, and acute migraine management. Pain 118:319-326. CrossRef Medline

Lipton RB, Bigal ME, Diamond M, Freitag F, Reed ML, Stewart WF (2007) Migraine prevalence, disease burden, and the need for preventive therapy. Neurology 68:343-349. CrossRef Medline

Maleki N, Becerra L, Brawn J, Bigal M, Burstein R, Borsook D (2012) Concurrent functional and structural cortical alterations in migraine. Cephalalgia 32:607-620. CrossRef Medline

Maleki N, Becerra L, Brawn J, McEwen B, Burstein R, Borsook D (2013) Common hippocampal structural and functional changes in migraine. Brain Struct Funct 218:903-912. CrossRef Medline

Maniyar FH, Goadsby PJ (2013) Functional imaging in chronic migraine. Curr Pain Headache Rep 17:333. CrossRef Medline

Martins de Araujo C, Barbosa I, Lemos S, Domingues R, Teixeira A (2012) Cognitive impairment in migraine. Dement Neuropsychol 6:74-79.

McNair DM, Lorr M, Droppleman LF (1971) Profile of mood states, Educational and Industrial Testing Service. San Diego, CA.

Mechelli A, Price CJ, Friston KJ, Ashburner J (2005) Voxel-based morphometry of the human brain: methods and applications. pp 105-113. CrossRef

Melzack R (1987) The short-form McGill Pain Questionnaire. Pain 30:191-197. Medline

Messina R, Rocca MA, Colombo B, Valsasina P, Horsfield MA, Copetti M, Falini A, Comi G, Filippi M (2013) Cortical abnormalities in patients with migraine: a surface-based analysis. Radiology 268:170-180. CrossRef Medline

Napadow V, LaCount L, Park K, As-Sanie S, Clauw DJ, Harris RE (2010) Intrinsic brain connectivity in fibromyalgia is associated with chronic pain intensity. Arthritis Rheum 62:2545-55. CrossRef Medline

Pires C, Sole E, Miro J (2013) Catastrophizing and pain impact in migraineurs. J Headache Pain 14:147.

Ploghaus A, Tracey I, Clare S, Gati JS, Rawlins JN, Matthews PM (2000) Learning about pain: the neural substrate of the prediction error for aversive events. Proc Natl Acad Sci U S A 97:9281-9286. CrossRef Medline

Ploghaus A, Narain C, Beckmann CF, Clare S, Bantick S, Wise R, Matthews PM, Rawlins JN, Tracey I (2001) Exacerbation of pain by anxiety is associated with activity in a hippocampal network. J Neurosci 21:9896-9903. Medline

Raichle ME, MacLeod AM, Snyder AZ, Powers WJ, Gusnard DA, Shulman GL (2001) A default mode of brain function. Proc Natl Acad Sci U S A 98:676-682. CrossRef Medline

Rocca MA, Ceccarelli A, Falini A, Colombo B, Tortorella P, Bernasconi L, Comi G, Scotti G, Filippi M (2006) Brain gray matter changes in migraine patients with T2-visible lesions: a 3-T MRI study. Stroke 37:1765-1770. CrossRef Medline

Sandkuhler J (2007) Understanding LTP in pain pathways. Mol Pain 3:9. CrossRef

Schmidt-Wilcke T, Leinisch E, Straube A, Kampfe N, Draganski B, Diener HC, Bogdahn U, May A (2005) Gray matter decrease in patients with chronic tension type headache. Neurology 65:14831486. CrossRef Medline 
Schmidt-Wilcke T, Gänßbauer S, Neuner T, Bogdahn U, May A (2008) Subtle grey matter changes between migraine patients and healthy controls. Cephalalgia 28:1-4. CrossRef Medline

Schmitz N, dmiraal-Behloul F, Arkink EB, Kruit MC, Schoonman GG, Ferrari MD, van Buchem MA (2008) Attack frequency and disease duration as indicators for brain damage in migraine. Headache 48:1044-1055. CrossRef Medline

Schweinhardt P, Kuchinad A, Pukall CF, Bushnell MC (2008) Increased gray matter density in young women with chronic vulvar pain. Pain 140:411-419. CrossRef Medline

Seeley WW, Menon V, Schatzberg AF, Keller J, Glover GH, Kenna H, Reiss AL, Greicius MD (2007) Dissociable intrinsic connectivity networks for salience processing and executive control. J Neurosci 27:2349-2356. CrossRef Medline

Seminowicz DA, Davis KD (2006) Cortical responses to pain in healthy individuals depends on pain catastrophizing. Pain 120: 297-306. Medline

Shackman AJ, Salomons TV, Slagter HA, Fox AS, Winter JJ, Davidson RJ (2011) The integration of negative affect, pain and cognitive control in the cingulate cortex. Nat Rev Neurosci 12:154-167. CrossRef Medline

Spreng RN, Mar RA, Kim AS (2009) The common neural basis of autobiographical memory, prospection, navigation, theory of mind, and the default mode: a quantitative meta-analysis. J Cogn Neurosci 21:489-510. CrossRef Medline

Spreng RN, Sepulcre J, Turner GR, Stevens WD, Schacter DL (2013) Intrinsic architecture underlying the relations among the default, dorsal attention, and frontoparietal control networks of the human brain. J Cogn Neurosci 25:74-86. CrossRef

Sridharan D, Levitin DJ, Menon V (2008) A critical role for the right fronto-insular cortex in switching between central-executive and default-mode networks. Proc Natl Acad Sci U S A 105:1256912574. CrossRef Medline
Stewart WF, Lipton RB, Kolodner KB, Sawyer J, Lee C, Liberman JN (2000) Validity of the Migraine Disability Assessment (MIDAS) score in comparison to a diary-based measure in a population sample of migraine sufferers. Pain 88:41-52. Medline

Sullivan MJ, Bishop SR, Pivik J (1995) The Pain Catastrophizing Scale: development and validation. Psychol Assess 7:524-532. CrossRef

Sullivan MJ, Thorn B, Haythornthwaite JA, Keefe F, Martin M, Bradley LA, Lefebvre JC (2001) Theoretical perspectives on the relation between catastrophizing and pain. Clin J Pain 17:52-64. Medline

Taylor KS, Seminowicz DA, Davis KD (2009) Two systems of resting state connectivity between the insula and cingulate cortex. Hum Brain Mapp 30:2731-2745. CrossRef Medline

Valfre W, Rainero I, Bergui M, Pinessi L (2008) Voxel-based morphometry reveals gray matter abnormalities in migraine. Headache 48:109-117. CrossRef Medline

Van Damme S, Crombez G, Eccleston C (2004) Disengagement from pain: the role of catastrophic thinking about pain. Pain 107:70-76. Medline

Wei F, Xu ZC, Qu Z, Milbrandt J, Zhuo M (2000) Role of EGR1 in hippocampal synaptic enhancement induced by tetanic stimulation and amputation. J Cell Biol 149:1325-1334. Medline

Whitfield-Gabrieli S, Nieto-Castanon A (2012) Conn: a functional connectivity toolbox for correlated and anticorrelated brain networks. Brain Connect 2:125-141. CrossRef Medline

Wilder-Smith $\mathrm{CH}$, Schindler D, Lovblad K, Redmond SM, Nirkko A (2004) Brain functional magnetic resonance imaging of rectal pain and activation of endogenous inhibitory mechanisms in irritable bowel syndrome patient subgroups and healthy controls. Gut 53:1595-1601. CrossRef Medline

Zheng F, Khanna S (1999) Hippocampal field CA1 interneuronal nociceptive responses: modulation by medial septal region and morphine. Neuroscience 93:45-55. Medline 